\title{
On Comparative Analysis of Two Ant Colony's Optimal Selectivity Decisions for Best Food Source Versus Migration to Well Protected Nest Site (Neural Networks' Approach)
}

\author{
Hassan M. H. Mustafa and Fadhel Ben Tourkia
}

\begin{abstract}
This piece of research presents a comparative analytical study for two diverse, challenging, and interdisciplinary decision making issues. Herein, that presented comparative study associated with two behavioral, intelligent, and interactive lifestyle decisions for Ant Colony agents' interaction with their environmental living conditions. In more details, the adopted presented analytical study considers the neural networks modeling for performance evaluation of the optimal selectivity decisions responding to two diverse behavioral lifestyles issues as follows.

The first issue is tightly related to the optimal decision making for increasing Ant Colony's foraging efficiency while reaching a selected best food source. More precisely, in a general sense, social insect colonies live in a dynamic, competitive environment in which food sources of variable quality are constantly changing in location. When more than one trail is present at a time, the interactions between foragers and the trails can lead to the collective selection of the shortest path or the best food source additionally, most of ant colony species are dependent upon ephemeral food finds, and in such living environment. There is an advantage of sharing mutual information if it can help the colony direct its workers quickly to an optimally selected the best of food sources.

The second issue is observed while ant insects are famous for their elaborate nest architecture; less well-known is their skill at moving from one nest site to another. Some, like army ants, move so often that they make no permanent structure, bivouacking instead in simple natural shelters. When an ant was tethered inside an unfamiliar nest site location, and unable to move freely, it is capable to release an alarming pheromone from its mandibular gland that signaled other ants to reject this nest site as to avoid presumable danger. Consequently, all of the colony's ant mates moves to well protected (sheltered) nest site. Interestingly, Artificial Neural Networks' $\left(\mathrm{ANN}^{\mathrm{S}}\right)$ modeling has been adopted as a realistic comparative tool for the study of both behavioral learning suggested issues.
\end{abstract}

Keywords-Artificial Neural Networks Modeling, Swarm Intelligence, Tandem Running, House Hunting Ants, Computing. Alarm Pheromone, Collective Decision Making, Temnothorax.

\section{INTRODUCTION}

The Ant is one type of social insects that have been evolved from wasp-like ancestors in the mid-Cretaceous of the

Hassan M. H. Mustafa and Fadhel Ben Tourkia both are with the Computer Engineering Department, Al-Baha Private College of Sciences AlBaha, Kingdom of Saudi Arabia period between 110 and 130 million years ago. It means they are as old as dinosaurs but unlike them, ants managed to survive. In a general sense, ant colonies as a social insect are living in a competitive, and dynamical environment. Which characterized by constantly changing food sources in their location (distributed sites), and variation of their quantity and quality. Most of ant species are dependent upon ephemeral food finds. In such an environment, there is an advantage to sharing information if it can help the colony direct its workers quickly to the best food sources. The second paradigm considers collective intelligence as a behavior that emerges through the interaction and cooperation of large numbers of lesser intelligent agents (such as ants). This paradigm composed of two dominant sub-fields 1) Ant Colony Optimization that investigates probabilistic algorithms inspired by the foraging behavior of ants [1][2], and 2) Particle Swarm Optimization that investigates probabilistic algorithms inspired by the flocking and foraging behavior of birds and fish [3]. Like evolutionary computation, swarm intelligence-based techniques are considered adaptive strategies and are typically applied to search and optimization domains. That simulation the foraging behavioral intelligence of a swarm (ant) system used for reaching optimal solution of Travelling Salesman Problem (TSP) a cooperative learning approach to the traveling salesman problem optimal solution of TSP considered using realistic simulation of Non-neural systems namely: ACS. In the context of intercommunications and cooperative learning among ants inside ACS. some interesting findings have been announced at [4]. about ants as the particular insect has been selected as a title (Aayat) of a Surah No.27 "The Ants" in the Noble Qur'an. Therein, it has been shown some interesting findings regarding ants' lifestyle intercommunication as follows :

a. The ants bury their dead in a manner similar to the humans.

b. They have a sophisticated system of division of labour.

c. Once in a while they meet among themselves to have a 'chat'.

d. They have an advanced method of communication among themselves. 
e. They hold regular markets wherein they exchange goods.

f. They store grains for long periods in winter and if the grain begins to bud, they cut the roots, If the grains stored by them get wet due to rains, they take these grains out into the sunlight to dry, and once these are dry, they take them back inside. Social insects have evolved impressively sophisticated solutions to some challenging enviornmental issues such as making nest site selection via building a leading model system of the collective intelligence of animal insect groups Temnothorax ants.

This manuscript is an interdisciplinary research article motivated by some behavioral observations for Ant Colony's optimal selective decision making. Firstly, the problem which considers selection between two food sources, one of these sources contains higher amount of sugar than the other. Both of sources are equidistantly sited at away from the original home nest Ant colony site [5].

Herein, an evaluation of the two above sugested issues is presented at this paper, considering the involvement of tandem running, and the self-organized mechanism (collective decision making). That's pointing out to perform optimal convergence of tandem running process directing towards the either better source with trails marked by higher pheromone (for the first problem). Or directing the way to -even distant best nest site (for the second problem). In more details, the ants recruited as foragers visited the source higher in sugar marked results in the trail to it with greater amounts of pheromone than those visiting the source with lower in sugar. That optimal selective decision for food source is compared with finding of optimal (best) nest. That is following the tandem running regulation helping to carry over directions to new nests, in accordance with what has been recently announced by O'Shea-Wheller [6]: the process occurs in a decentralized fashion and is controlled by basic rules. Specifically, ants respond to the discovery rate of a new nest site, rather than by direct measurement of distance. "Colonies counteract the difficulty of finding a distant nest, simply by increasing the rate at which individuals give each other 'directions'," explains O'Shea-Wheller [6]. "This in turn increases the discovery rate, and contributes to a larger pool of informed workers. As such, the amount of directional information that a colony gathers increases as a function of migration distance, sort of like a self-organizing route planner.".. Specifically, the two problems achieve optimality of decisions by modulating the rate of "tandem running', in which ants workers teach each other the route to either a better food source or a new nest site. In brief, both of the suggested problems are autonomously (Self-organizing) perform selective searching considering speed-accuracy trade off for optimum decision to reach either best source or nest site. Briefly, this paper have demonstrated the comparison between two effective optimal selectivity decisions for : a) The best source location between two food sources that are equidistantly sited away from the original home nest, based upon pheromone trails and following the tandem running regulation [7][8] \& b) The balanced selection performance with the migration speed, in order to minimize exposure to a hostile environment to avoid presumable danger. That is based upon releasing alarming pheromone from the ants' mandibular gland and signaling other ants to reject dangerous nest site [8]. The rest of this paper is organized in four sections, in addition to this introduced first section. These sections are given in brief as follows. At the next second section revising of the optimal selective process of a food source is presented. A review of ant colony migration strategies from the home nest to another non-vulnerable one to any potential danger is given at the third section. At the fourth section, obtained simulation results are given. Finally, some interesting conclusive remarks are introduced at the last fifth section.

\section{ANT'S SELECTION OF BEST FoOd SOURCE}

\section{A. Selection between Two Pawthays using Pheromones' Marking}

If an experimenter offers a colony of mass recruiting ants, one of the species using pheromones to food trails, two food sources simultaneously and at equal distances from the nest, but one is higher in sugar content than the other, most of the foragers will usually go to the source higher in sugar. Some of the foragers will feed from the source lower in sugar, but on the average, their numbers will be much lower than those going to the better source. This is of course a good decision for the survival and reproduction of the colony: the ants concentrate on the food source that provides the most calories with the least amount of effort. But how do they do this? How do they "decide" which source is better and how do they coordinate their efforts so as to exploit it preferentially?.[5]. Herein, a proposed explanation is currently introduced for how towards the better source containing the greatest amounts of pheromone and differentially choose these trails over those to lesser sources marked with smaller amounts of pheromone, illustration of how a group of ants able to optimally decide the selectivity of a shorter path to reach the food source via an asymmetrical simplified bifurcations network (referring to Fig.1.). It is noticed clearly that amount of artificial pheromone that is added depends on the length of the chosen path: the shorter the path, the higher the amount of added pheromone. 


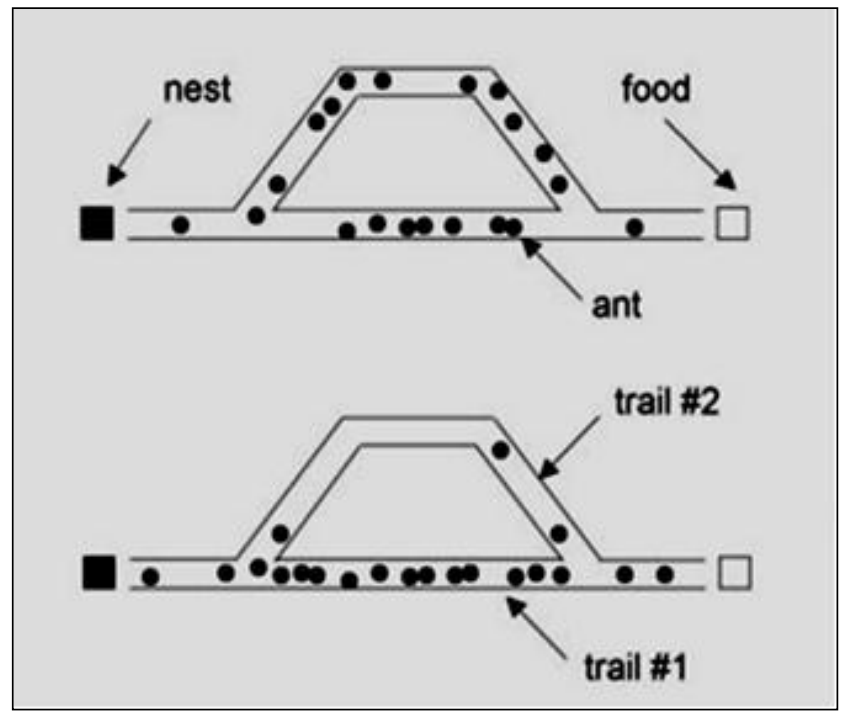

Fig. 1: Schematic illustration of the ant algorithm. (At the top). Selection of a shorter path between a nest and a food source by natural ants. The ants travel between the nest and food through trail $\# 1$ and trail \#2. Initially, ants are distributed equally on both trails.

(At the bottom). Since trail \#1 is shorter than trail \#2, trail \#1

becomes their favorite pathway with a higher pheromone concentration. (Adapted from[9])

\section{B. Selection of Minimum Pathway Between Source and Nest}

Referring to Fig.2, in the case of bifurcation occurrence due to an existence of an obstacle at some point placed on the pathway between the nest site and that of the source, the transportation process of food (from food source) to food store (nest). is illustrated behavioral ants' responses shown at the simplified sketched figure considering the pheromone trail between nest and food source.

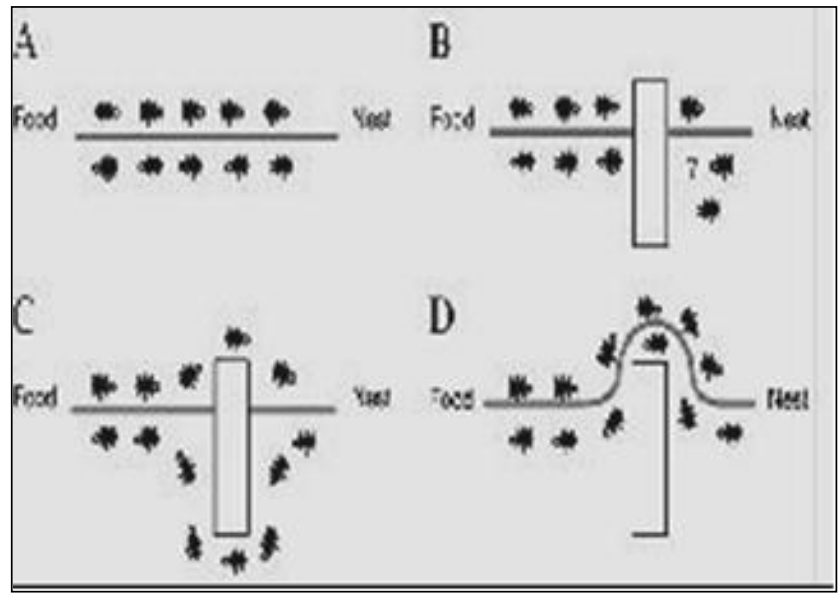

Fig. 2: Ant Behavior A. Ants in a pheromone trail between nest and food; B. An obstacle interrupts the trail; C. Ants find two paths to go around the obstacle; D. A new pheromone trail is formed along the shorter path.

Accordingly, the persistent or recurring food sources may also be available, such as the aphids or scale insects 'farmed' by many ant species. The best strategy is often to remember rewarding foraging sites but also to be flexible enough to exploit newly discovered food and to select the better sources from those available. To this end, information directing nestmates to food also enables them to select the highest quality food find when multiple resources are available [1].

Selection of one Path Between Two Diamond's Branches

Referring to [10], it is announced that, one of the most striking features of an ant colony's behaviour is its capacity for the spatial organisation of foraging activity. The use of trail pheromone to guide fellow workers in the nest to a large food source or rich foraging zone has been extensively studied [11] and obviously contributes to foraging efficiency. We have recently, however, been able to show that trail laying and trail following behaviour are more than just a means of communicating a food source's location. When more than one trail is present at a time, the interactions between foragers and the trails can lead to the collective selection of the shortest path or the best food source, despite the fact that individual foragers have no means of making such choices. Referring to the published research work at [12], it reveals the importance of the shape of trail networks for foraging in ants and emphasizes the underestimated role of the geometrical properties of transportation networks in general. At Fig.3, Ants moved searching the way to a food source via Symmetrical Diamond Bridge having two identical branches.

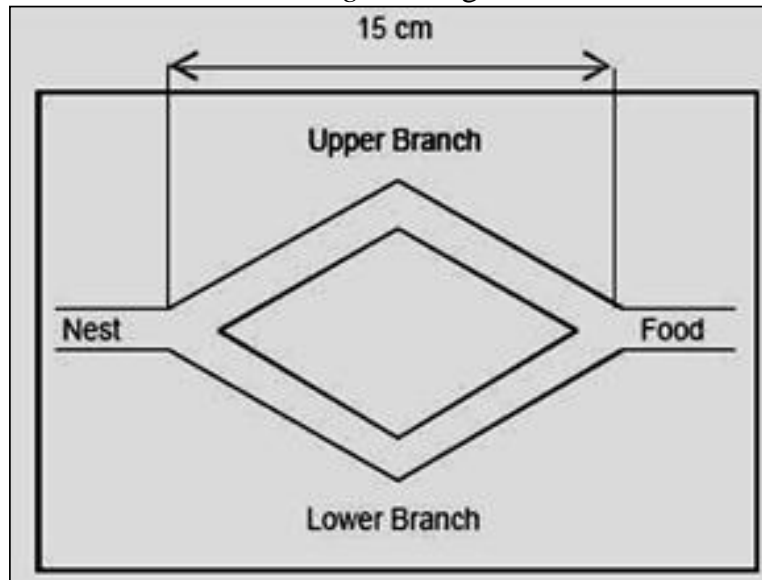

(a)

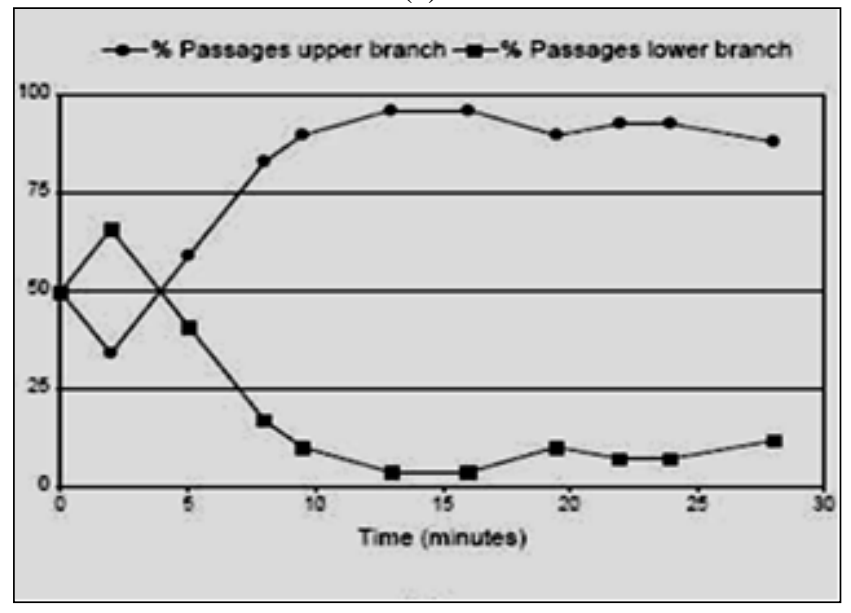

(b)

Fig..3: (a) illustrates a diamond bridge composed of two identical branches. The ants pass through that bridge adopting bifurcation (distributed) Strategy (b) Percentage of the ant workers per three minutes period that are passing on the two(upper and lower) branches of the diamond bridge (Adapted from [13]) 


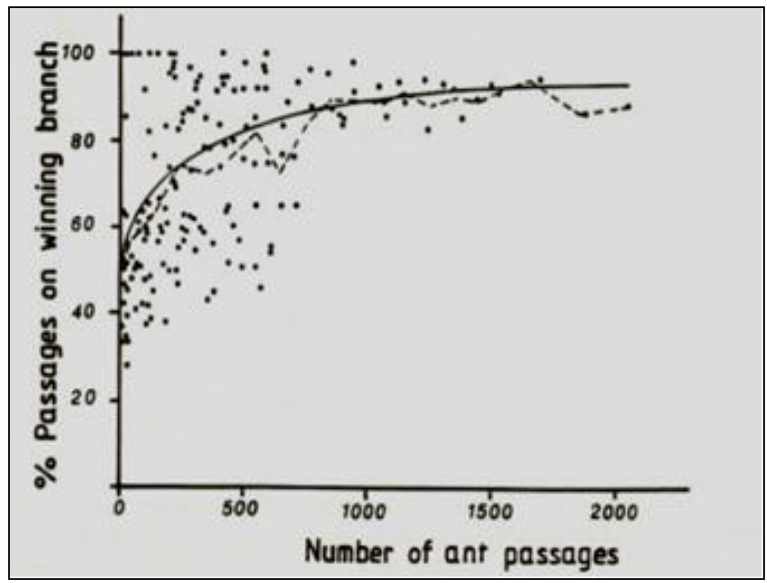

Fig. 4: Percentage of the ant workers that are passing on the collectivity selected winning branch of the diamond bridge \{ shown at the above Fig.3) \} resulting after 20 experiments measured every three minutes(dotes). Noting that horizontal axis represents the cumulative number of ant passages on both branches of the diamond bridge. The

dashed curve represents the average values. The solid curve represents the average of 200 monte-Carlo Simulations.(Adapted from[10])

\section{ORganiZATION OF COLONY MigRATION}

Migratory behavior forms an intrinsic part of the life histories of many organisms but is often a high-risk process. Consequently, varied strategies have evolved to negate such risks, but empirical data relating to their functioning are limited. In this section, recruitment of signals used by successful foragers or nest site scouts, concerned with but another fundamental type of communication is alarm signaling. In social insects [8], defensive behavior is closely connected with alarm signals that either recruit nest-mates to combat a potential-danger or warn them to stay away [8] [14][15][16].

\section{A. Selection between Two Target Nests}

In the general sense, the social insects are famous for their elaborate nest architecture; less well-known is their skill at moving from one nest site to another. Some, like army ants, move so often that they make no permanent structure, bivouacking instead in simple natural shelters. Others, like honeybees and polybiine wasps, build elaborate nests, but emigrate to new homes during colony reproduction. Still others, like ants of the genus Temnothorax, are often forced to move because of the fragility of their nests. House-moving is one of the most challenging tasks a colony faces. Its future success depends on finding a home that offers the right physical environment, protection from enemies, and access to resources. At the same time, choosiness must be balanced with speed, to minimize exposure to a hostile environment, and to prevent delays in growth and reproduction. In most cases, consensus must be reached among hundreds or thousands of individuals, lest the colony should divide among multiple sites to the detriment of all. Finally, all of this must be achieved without well-informed leaders or central control. Instead, the work of selecting and moving to a home is distributed across a population of workers, each informed about only a limited number of options, and influencing only a portion of its nest mates. More specifically, in this paper the model system of the house hunting ant Temnothorax albipennis is adopted, that to demonstrate a key strategy that can shorten migration exposure times in a group of social insects. Colonies of these ants frequently migrate to new nest sites, and due to the nature of their habitat, the distances over which they do so are variable, leading to fluctuating potential costs dependent on migration parameters.

Referring to [8], the migratory behavior forms an intrinsic part of the life histories of many organisms but is often a highrisk process. Consequently, varied strategies have evolved to negate such risks, but empirical data relating to their functioning are limited. In this study, we use the model system of the house hunting ant Temnothorax albipennis to demonstrate a key strategy that can shorten migration exposure times in a group of social insects. Colonies of these ants frequently migrate to new nest sites, and due to the nature of their habitat, the distances over which they do so are variable, leading to fluctuating potential costs dependent on migration parameters. Regarding to the closest resemblance of ants' lifestyle with respect to that of human beings. local advanced intercommunication observed via chatting signaling among colonies' agents (ants). These signaling findings have been basically originated in accordance with the intercommunicative distributed collective cognition decisions among ants' colony members. Specifically, in the case of anticipated danger analysis, evaluation and deciphering of emerged alarm communication signals against predators resulting in variety of behavioral responses. In more details, considering the colony of Temnothorax rugatulus, it has been reported that alarm signaling pheromone while electing two different behaviors is dependable upon different context.

\section{B. Binary Choice between Two Nests [8]}

Referring to Fig.5, when an ant was tethered inside an unfamiliar nest site and unable to move freely, she released a pheromone from her mandibular gland that signaled other ants to reject this nest as a potential new home, presumably to avoid potential danger. Accordingly, it is clearly possible that this pheromone's function can improve an emigrating behavioral response for colony's nest site selection performance. Colonies were given a binary choice between a nest with tethered ants and a nest that had five strings but no ants. By referrig to Fig. 8 concerned with test arena, were given a binary choice between a nest with tethered ants and a nest that had five strings but no ants. These two target nests were first placed adjacent to one another against one wall of the test arena.The home nest containing the colony from which the tethered ants were taken was then placed against the center of the wall opposite to the location of the target nests. Finally, the roof of the home nest was removed to induce migration. 


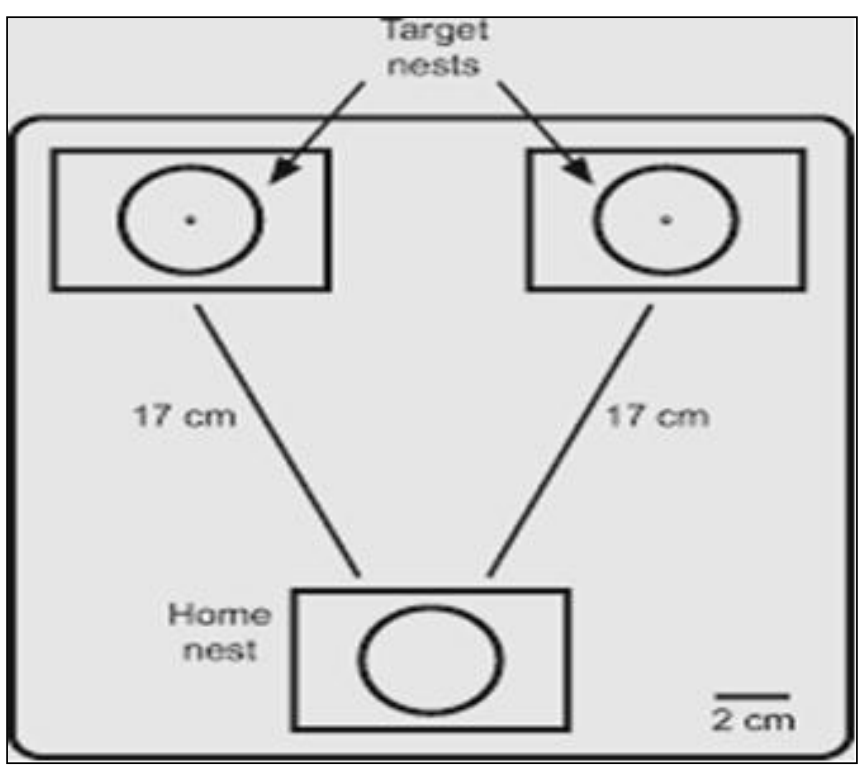

Fig.4: Experimental arena for nest choice tests. Colonies initially lived in the home nest, from which the roof was removed to induce migration. Colonies were allowed to choose between two target nests, which were identical in design but contained different materials (see Materials and methods for details). The arena size was $20 \times 20 \mathrm{~cm}$ and $1 \mathrm{~cm}$ in height.(Adapted from [8]).

The binary selection (choice) of one target nest between the equidistantly two targets is originally based upon the collective decision making [8]. That is carried out by ant workers' migratory performance from home nest towards the selected target nest in accordance with the signalling originated from Alarm Pheromone to avoid dangerous hostile direction. Obviously, the ant workers' behavioral passing function (via selected target nest direction), results in performance closely resembling to the selected winning branch of the diamond bridge (shown at the above Fig.3) and (Fig.4), adapted from[10]\}.

\section{SimULATION RESUlT}

The presented simulation results have been in agreement with and supported by some obtained realistic computer modeling results, and announced findings published at a set of pieces of research manuscripts [17],[18],[19],[20],[21],[22], and [23]. Referring to Fig.6 \& Fig.9., the performance of an Ant Colony via the winning branch reaches some percentage value [\%] after passing collectively a group of ant workers (supervised learning). This performance is dependable upon individual differences of ant colonies. This differences are simulated by Fig.9, while reaching the solution of TSP with different values of either intercommunication parameters among ant colony agents, or learning rate values. Referring to the two figures (Fig.7\&Fig.8), are simulating the performance of the first and second issues respectively. Furthermore, the different learning rate values $\{\eta=0.05,0.1$, and 0.2$\}$ are analogous to different intercommunication values among ant agents. That is by considering supervised, and self-organized learning responses respectively presented by (Fig.7, and
Fig.8). It is noticed that resulted in convergence to different relative error values $\mathrm{e}(\mathrm{n})$ percentage values [\%]. After any fixed time period \{number of trials (n)\}. Moreover, the two sets, each of three curves at Fig.5, are analogous to the results shown at Fig.5 However, the rate corrosponding to set in Fig.5(a) is less tham that at the set in Fig.5(b). That is due the last set(b), is more valurable to danger than the former set (a) [6].

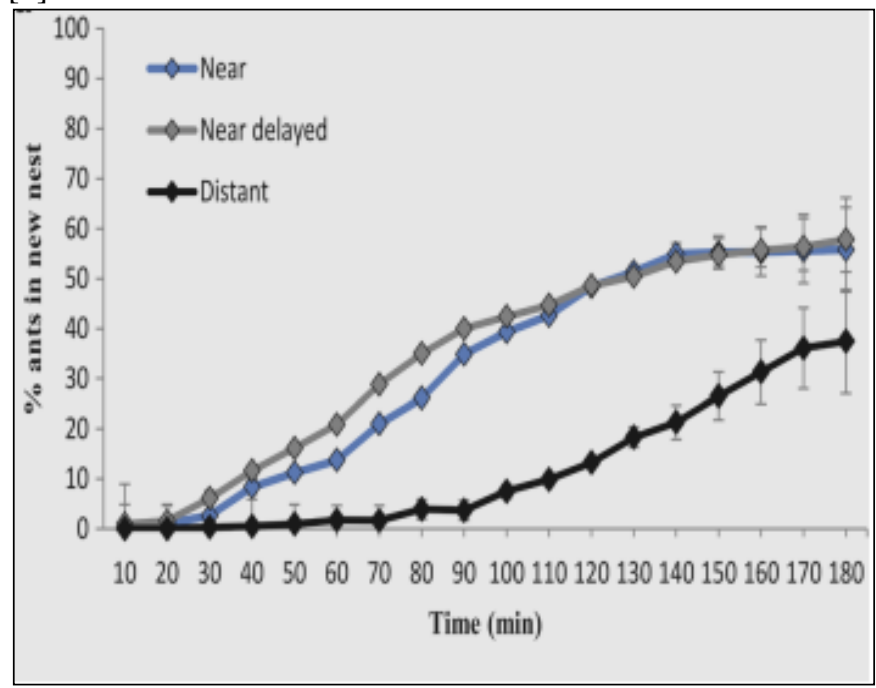

(a)

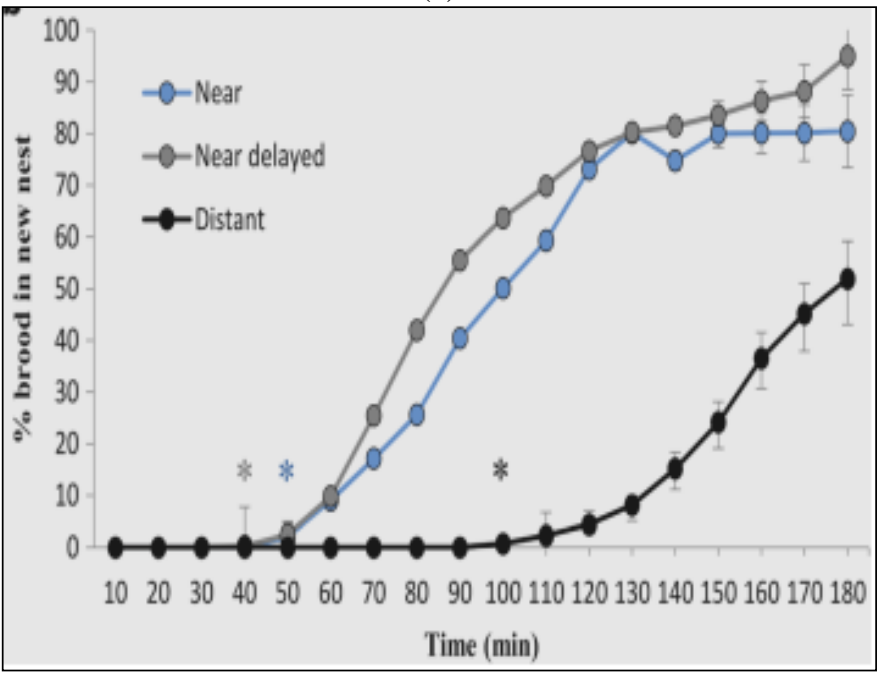

(b)

Fig. 5: Mean percentage of total colony workers (a) and brood (b) in the new nests over time for each of the three treatment groups. Blue lines indicate the near treatment, grey lines indicate the near delayed treatment and black lines indicate the distant treatment, \{ Adapted from[6]\}. 
Average Speed to

Optimum Solution (1Sec.)

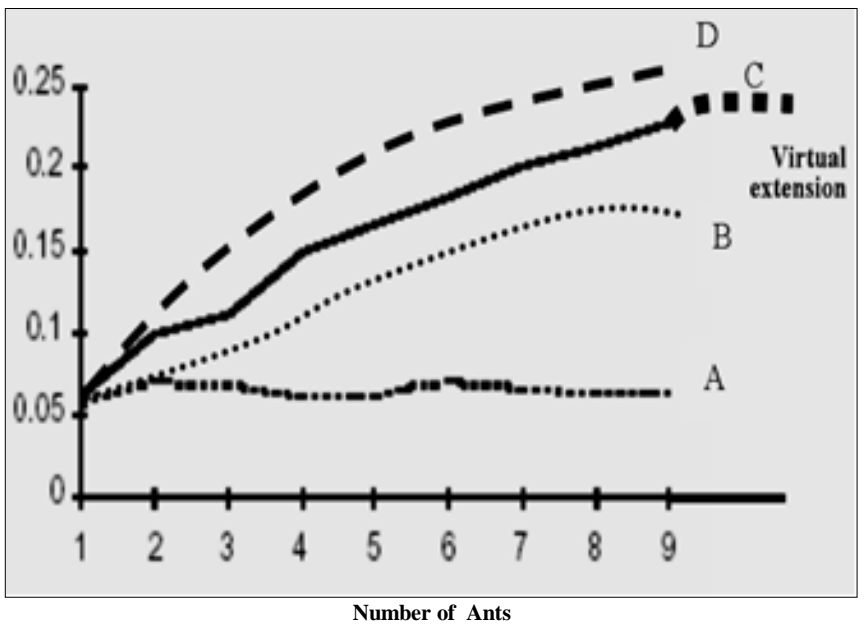

Fig. 6: Communication determines a synergistic effect with different inter communication levels among agents leads to different values of average speed to reach the optimal solution of the T S P.\{Adapted

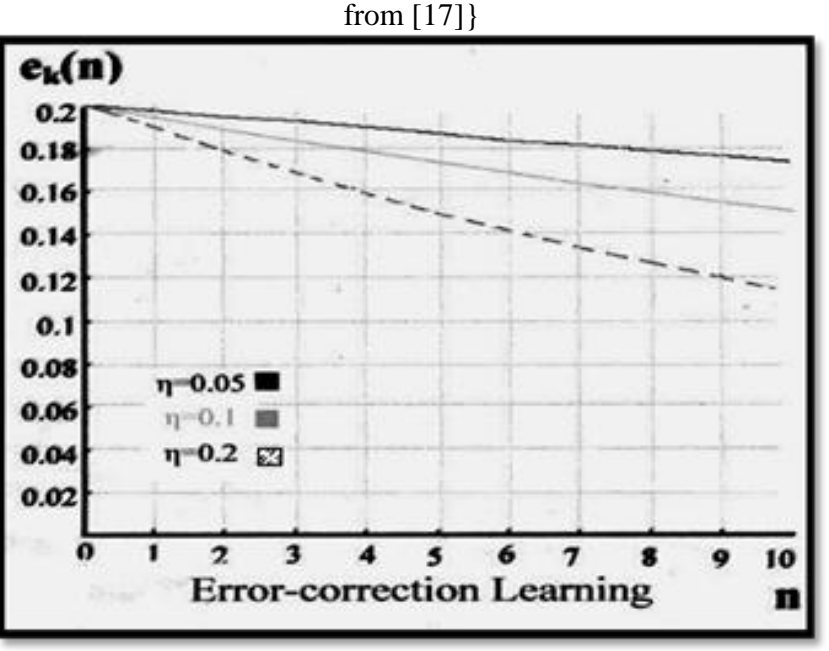

Fig. 7: Adaptability performance concerned with error correction (supervised) learning algorithm with learning rates $(0.05,0.1,0.2)$

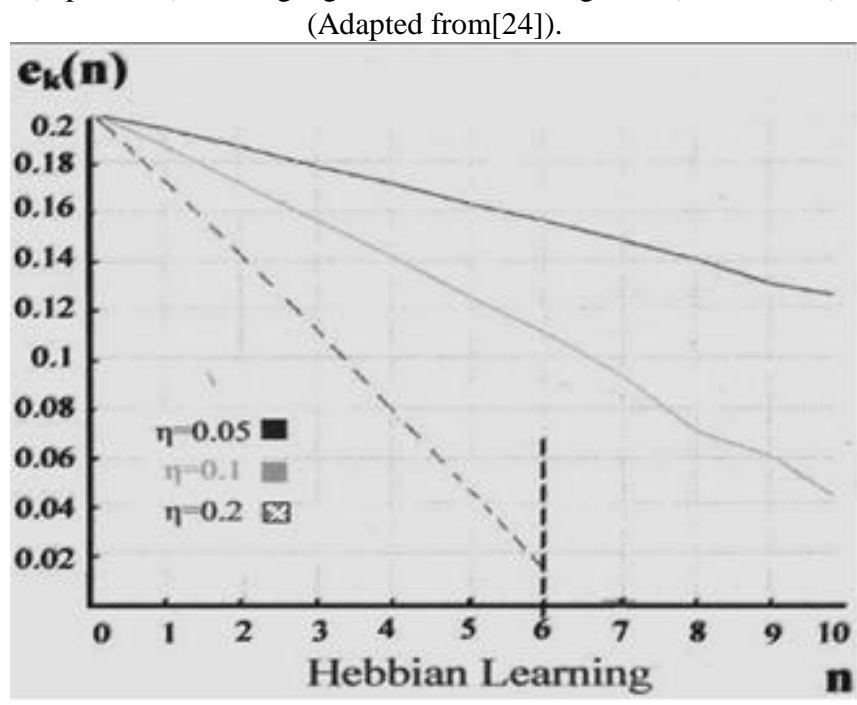

Fig. 8: Adaptability performance concerned with Hebbian (selforganized) learning algorithm with learning rates $(0.05,0.1,0.2)$.

(Adapted from[24])

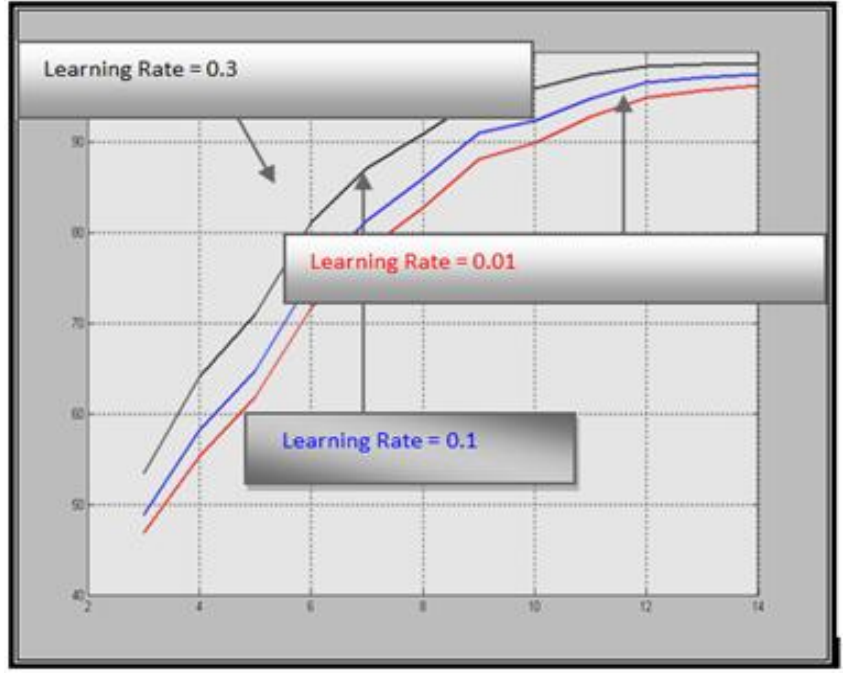

Fig. 9: Illustrates simulated outcome presented as percentage degree of lesson focusing versus \# Neurons. for different learning rate values $(0.3,0.1$, and 0.01$)$.

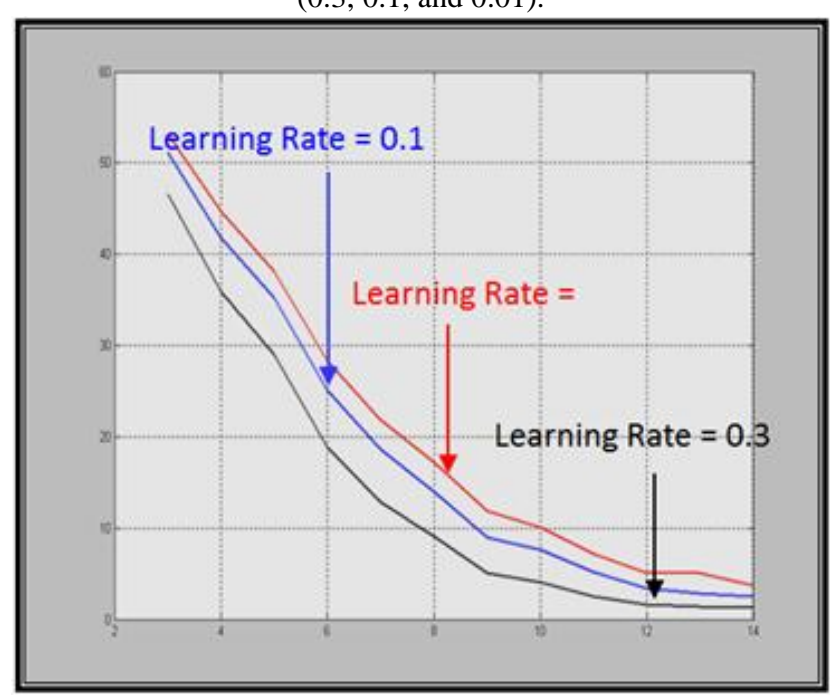

Fig. 10: Illustrate learning performance error-rate with different learning rates when \#cycles $=300$ and gain factor $=1$

\section{V.CONCLUSIONS}

This piece of research comes to two interesting conclusive remarks presented as follows:

- The existence of an obstacle at some point of ants' pathway (Fig.2), results in various trailing pheromone tracing. Due to asymmetry of obstacles' shape, the time needed to find the shorter pathway is directly proportional to the discovery of the minimum path.

- The humble ant is not only capable of solving difficult mathematical problems, but is even able to do what few computer algorithms can - adapt the optimal solution to fit a changing problem, deepen our understanding of how even simple animals can overcome complex and dynamic problems in nature, and will help computer scientists develop even better software to solve logistical problems and maximize efficiency in many human industries. 


\section{REFERENCES}

[1] E. Bonabeau, M. Dorigo, and G. Theraulaz. Swarm Intelligence: From Natural to Artificial Systems. Oxford University Press US,999.

[2] M. Dorigo and T. St $\square$ utzle. Ant Colony Optimization. MIT Press, 2004.

[3] J. Kennedy, R. C. Eberhart, and Y. Shi. Swarm Intelligence. Morgan Kaufmann, 2001.

[4] How ants communicate? Available on line at http://www.youtube.com/watch?v=gcHt5n3NGK0 Uploaded on Jul 28, 2011.

[5] Ivan D. Chase, Abhijit V. Deshmukh \& Naga Krothapalli:" How do Ants Decide Between Food Sources of Different Values? An evaluation of the Current Explanation and Associated Mathematical Models" Published at the PROCEEDINGS of the 2nd International Workshop on the Mathematics and Algorithms of Social Insects Georgia Institute of Technology, Atlanta, GA.30332, December 15-17, 2003, pp. 41-46.

[6] O'Shea-Wheller, T. A. et al. (2016). Migration control: a distance compensation strategy in ants, The Science of Nature, DOI 10.1007/s00114-016-1386.

[7] Hassan M. H. Mustafa, and Fadhel Ben Tourkia "On Comparative Analysis and Evaluation Of Social Insect Colonies' Behavior During Exploring Food Sources and Their Migration to A New Nest Versus Two of Neural Networks' Learning Paradigms. (Tandem Running Approach)" Published Journal IJATTMAS volume III issue xI nov 2017 Page 33-41.

[8] Sasaki, Bert Hölldobler, Jocelyn G. Millar, Stephen C. Pratt "A contextdependent alarm signal in the ant Temnothorax rugatulus" . .Pubished at the Journal of Experimental Biology 2014 217: 3229-3236; doi: 10.1242/jeb.106849.-Available-online-at: http://jeb.biologists.org/content/217/18/3229

[9] Yunlong Liu and Hiroki Yokota " Artificial ants deposit pheromone to search for regulatory DNA elements".Available online at:

https://bmcgenomics.biomedcentral.com/articles/10.1186/1471-2164-

7-221.Published: 30 August 2006.The-image-available-onlineat:http://media.springernature.com/full/springerstatic/image/art:10.1186/1471-2164-7221/MediaObjects/12864_2006_Article_604_Fig1_HTML.jpg

[10] S. Goss, R. Beckers,J. L. Deneubourg, S. Aron, J. M. Pasteels " How Trail Laying and Trail Following can Solve Forgaring Problems For Ant Colonies" Behavioural Mechanisms of Food Selection pp 661-678. NATO AS! Series, Vol. G 20 Behavioural Mechanisms of Food Selection Edited by R. N. Hughes ( $)$ Springer-Verlag Berlin Heidelberg 1990. Available online at: https://link.springer.com/content/pdf/10.1007/978-3-642-75118 9_32.pdf

[11] Wilson EO (1971). The insect societies. Harvard University Press, Cambridge Massachussets

[12] Simon Garnier, Maud Combe, Christian Jost, and Guy Theraulaz "Do Ants Need to Estimate the Geometrical Properties of Trail Bifurcations to Find an Efficient Route? A Swarm Robotics Test Bed". Published: on March 28, 2013.

[13] Deneubourg JL, Aron S, Goss S, Pasteeis JM. (1989a) The selforganizing exploratory pattern of the Argentine ant. J Ins Behav in press.

[14] Blum, M. S. (1969). Alarm pheromones. Annu. Rev. Entomol. 14, 5780. https://doi.org/10.1146/annurev.en.14.010169.000421

[15] Blum, M. S. (1985). Alarm pheromones. In Comprehensive Insect Physiology, Biochemistry and Pharmacology: Behaviour, Vol. 9 (ed. G. A. Kerkut and L. I. Gilbert), pp. 193-224. New York, NY: Pergamon Press.

[16] Crewe, R. M. and Fletcher, D. (1974). Ponerine ant secretions: the mandibular gland secretion of Paltothyreus tarsatus Fabr. J. Entomol. Soc. South Africa 37, 291-298.

[17] H. M. Hassan. "On Learning Performance Evaluation for Some PsychoLearning Experimental Work versus an Optimal Swarm Intelligent System.", Published at ISSPIT 2005 (18-20 Dec.2005). $\mathrm{http}: / /$ ieeexplore.ieee.org/xpl/login.jsp?tp=\&arnumber=1577175\&url=ht tp\%3A\%2F\%2Fieeexplore.ieee.org\%2Fxpls\%2Fabs_all.jsp\%3Farnumb er\%3D1577175

[18] H.M. Hassan, "On Mathematical Modeling of Cooperative E-Learning Performance During Face to Face Tutoring Sessions (Ant Colony System Approach)"published at IEEE EDUCON 2011,on Education
Engineering-Learning Environments and Ecosystems in Engineering Education, held on April 4-6, 2011,Amman, Jordan. Available on line at:

http://www.google.com.sa/url?sa=t\&rct=j\&q=\&esrc=s\&frm=1\&source= web\&cd=9\&ved=0CHQQFjAI\&url=http $\% 3 \mathrm{~A} \% 2 \mathrm{~F} \% 2 \mathrm{Feditlib}$. org $\% 2 \mathrm{Fd}$ $\% 2 F 45687 \&$ ei=rsUFU66SAc-

c0wWakIHAAQ\&usg=AFQjCNFXdog2WcQE_3DE5-8sVp7aaVH4Lw

[19] H.M. Mustafa "A tutorial titled: Building up bridges for natural inspired computational models across behavioral brain functional phenomena; and open learning systems", that has been presented at the International Conference on Digital Information and Communication Technology and its Applications

(DICTAP 2011) held at Universite de Bourgogne, Dijon, France. (June 21-23, 2011). Available online at: http://dictap2011.sdiwc.us/tutorials.php

[20] Hassan M. H. Mustafa, and Fadhel Ben Tourkia "On Analysis and Evaluation of Learning Creativity Quantification via Naturally Neural Networks' Simulation and Realistic Modeling of Swarm Intelligence" published at the proceeding of the conference Eminent Association of Researchers in Engineering \& Technology(EARET).To be held on 8-9 January 2018.

[21] Hassan M. H., et.al"On Comparative Analogy between Ant Colony Systems and Neural Networks Considering Behavioural Learning Performance" Journal of Computer Sciences and Applications, 2015, Vol. 3, No. 3, 79-89 Available online at http://pubs.sciepub.com/jcsa/3/3/4 @ Science and Education Publishing DOI:10.12691/jcsa-3-3-4. https://doi.org/10.12691/jcsa-3-3-4

[22] Hassan M. H. "Analytical Comparison of Swarm Intelligence Optimization versus Behavioral Learning Concepts Adopted by Neural Networks (An Overview) American Journal of Educational Researchhttp://pubs.sciepub.com/education/3/7/2/index.html Vol. 3, No. 7, 2015, pp 800-806. doi: 0.12691/education-3-7-2

[23] Hassan M. H., et.al "Comparative Performance Analysis and Evaluation for One Selected Behavioral Learning System versus an Ant Colony Optimization System" Published at the Proceedings of the Second International Conference on Electrical, Electronics, Computer Engineering and their Applications (EECEA2015), Manila, Philippines, on Feb. 12-14, 2015.

[24] Hassan M. H., et.al. "On Assessment of Brain Function Adaptability in Open Learning Systems Using Neural Networks Modeling (Cognitive Styles Approach). Journal of American Science 2011; 7(9): 238-247]. (ISSN: 1545-1003). http://www.americanscience.org. 